\title{
Analysis of the Interrelationships between the Prices of Sri Lankan Rubber, Tea and Coconut Production Using Multivariate Time Series
}

\author{
Kwadwo Agyei Nyantakyi", B. L. Peiris, L. H. P. Gunaratne \\ Postgraduate Institute of Agriculture, University of Peradeniya, Sri Lanka
}

Copyright (C) 2015 Horizon Research Publishing All rights reserved.

\begin{abstract}
With the globalization of the economy and the financial markets today, price movement of one market can spread easily and instantly to another market. Because of these financial markets are more or less dependent on each other, there is a need to study their interrelationships to understand the dynamic structure of the financial economy. In this paper, we use Vector Auto Regression (VAR) Analysis to study the interdependency of the price of tea, rubber and coconut production in Sri Lanka. We also measured the strength of the linear interrelationship between the assets using the $l a g-l$ cross-correlation matrix (CCM) and also fit a VAR-model using selection criteria based on the AIC, SIC and HQIC. We examined the individual behaviour of the separate prices of each asset and then analysed the combined effects of the prices. Out of all computing models, we observed that tea price was ARIMA $(0,1,0)$, rubber price was ARIMA $(3,1,1)$ and coconut price is ARIMA $(0,1,3)$. Thus they were all integrated of order $\mathrm{I}(1)$. We investigate if there is a cointegration between the assets to see if there was a long-run equilibrium, and there was at most one cointgretion equation. Hence we used the Vector Error Correction model (VECM), for the estimation. We observed that coefficients between any of the variables were not equal to zero. The coefficient estimates between tea and rubber were not the same as between rubber and tea at all lags, between tea and coconut, as well as between rubber and coconut. Which indicate that there may be feedback relationship between all the three series. Further, impulse response analyses were used to observe the impacts. There was a fairly strong correlation between them, hence it could be concluded that, there is a linear dependency of all the variables.
\end{abstract}

Keywords Cross-correlation Matrix, Cointegration, Vector Error Correction

\section{Introduction}

Agricultural sector plays very important role in Sri Lankan economy. From 2010-2012, it has approximately employed $31.3 \%$ annually for the labour force. The sector has also contributed approximate annual income of Rs 1307698 million from 2000-2012 as a support to the GDP of Sri Lanka (Department of Census and Statistics, 2013)[7]. Tea, rubber and coconut are some of the major agricultural commodities that contribute immensely to the GDP of Sri Lanka. They also serve as a key employment area for the economy.

Tea production in Sri Lanka is of high importance to the Sri Lankan economy and the world market. Sri Lanka is the fourth largest tea producer in the world. The tea industry is one of the country's main sources of foreign exchange and a significant source for employment. Tea is accounting for $12 \%$ of the GDP and generated roughly on the average of Rs 77212.33 million annually from 2011-2013. The tea sector currently employs directly or indirectly over one million people in Sri Lanka and in 1995 directly employed 215,338 on tea plantations and estates. Annual Report (2010-2011) $[6,13]$.

In the world, Sri Lanka is one of the nine major producers of natural rubber, and in terms of productivity, is now the third best following India and Indonesia. From 2011-2013, rubber has contributed on the average of Rs 46040 million per year to the GDP of Sri Lanka. The rubber sector employs directly or indirectly over one million people in Sri Lanka.

Coconut is one of the common food product found in Sri Lanka. From 2011-2013, coconut has contributed on the average Rs 71876.33 million per year to the GDP of Sri Lanka. The coconut estates employ directly or indirectly over one million people in Sri Lanka as well. (Department of Census and Statistics, 2013)

Various researchers have looked at different estimations of the returns on the individual crops, but we believe that with the globalization of the economy and the financial markets today, price movement of one market can spread easily and instantly to another market. Since these financial markets are more or less dependent on each other, there is a need to study their interrelationships to understand the dynamic structure of the financial economy. In this paper we 
use Vector Auto Regression (VAR) Analysis to study the interdependency of the returns on tea, rubber and coconut which are some of the important cash crops in Sri Lanka.

The objective of the study is to understand the dynamic structure of the financial economy. In order to achieve this objective, in particular, the study would explore the following specific objectives, to examine behaviour of the prices of the individual assets, to investigate the interrelationship between the prices of tea, rubber and coconut and the total behaviour of the effects of the prices on the assets.

The study will establish, if the price movement of one market can spread easily and instantly to another market which makes financial markets more or less dependent on each other, hence the need to study their interrelationships to understand the dynamic structure of the financial economy. This study is also done to add knowledge to the understanding of the interrelationship between these important plantation crops and their returns on the GDP of the Sri Lankan economy.

\section{Hypothesis:}

H0: There is interrelationship between the prices of tea, rubber and coconut

H1: There is no interrelationship between the prices of tea, rubber and coconut

\section{Materials and Methods}

\section{Data Source}

Annual secondary data was collected from FAOSTAT [9], food balance sheet, price statistics and from, Department of Census and Statistic Sri Lanka. These data comprises of the annual prices of tea, rubber and coconut from $1966-2009$. The estimates in real terms of the past data series were based on the constant prices of 1958, 1963, 1975 and 1990. The current price estimates were at current factor cost prices until 1975 and thereafter it was at current producer prices. The National Accounts estimates are compiled based on the UN guidelines given in the System of National Accounts (SNA), Ministry Of Statistics (2010)[11].

\section{Statistical Software}

The $\mathrm{R}$ software was used in analysing and fitting the VECM models.

\section{Behaviour of the Data}

Figure 1 is the time series plot showing the behaviour of the price of the variables tea, rubber and coconut between 1966-2009, with prices of rubber having a higher upward growth/movement than the others. Tea and rubber prices exhibit similar characteristics. Initially there was an increase in growth of tea prices from 1966-1998, however, there were sharp drops in 1999 and 2000.



Figure 1. Time series plot of the price of tea (blue colour), rubber (black colour) and coconut (red colour) in the period (1966-2009)

\section{Methodology}

Let $X_{1}, X_{2}$ and $X_{3}$ be the individual price of the assets tea, rubber and coconut respectively, and $X_{t}$ the total returns with $X_{t}=\left(X_{1 t}, X_{2 t}, X_{3 t}\right)^{\prime}$ of the assets at time $t$, where $a^{\prime}$ denotes the transpose of $a$. Then let a stochastic process $\{x$ $\left.{ }_{i t}: \mathrm{t} \in \mathrm{Z}\right\}$ be an autoregressive process of order $\mathrm{p}(\geq 1)$ (AR(P)-process),

$$
\begin{aligned}
& \mathrm{X}_{1 t}=\sum_{k=1}^{p} \alpha_{k} \mathrm{x}_{t-k}+\varepsilon_{t}, \quad-1<t<\infty, \alpha_{p} \neq 0 \\
& \mathrm{x}_{2 t}=\sum_{k=1}^{p} \alpha_{k} \mathrm{x}_{t-k}+\varepsilon_{t}, \quad-1<t<\infty, \alpha_{p} \neq 0 \\
& \mathrm{x}_{3 t}=\sum_{k=1}^{p} \alpha_{k} \mathrm{x}_{t-k}+\varepsilon_{t}, \quad-1<t<\infty, \alpha_{p} \neq 0
\end{aligned}
$$

where $\left\{\varepsilon_{t}\right\}$ is a white noise.

Richard and Johnson (2012) [12] and Anderson (1951, 1984) $[3,4]$ define the mean vector and the covariance matrix as:

$\mu=E\left(X_{t}\right)$ is the k-dimensional vector of the unconditional expectations of $X_{t}$ and

$$
\Gamma_{0}=E\left[X_{t}-\mu\right]\left[X_{t}-\mu\right]^{\prime}
$$

where $\Gamma_{0}$ is a $k \times \mathrm{k}$ matrix and $\mu=\left(\mu_{1}, \cdots, \mu_{k}\right)^{\prime}$ and the $(i, j)^{t h}$ element of $\Gamma_{0}$ is the covariance of $X_{i t}$ and $X_{j t}$.

Let $D$ be a $k \times \mathrm{k}$ matrix diagonal matrix consisting of the standard deviations of $X_{i t}$ for $i=1, \cdots, k$.

Then $D=\operatorname{diag}\left[\sqrt{\Gamma_{11}(0)}, \cdots \sqrt{\Gamma_{k k}(0)}\right.$

The lag-zero cross-correlation matrix (CCM) of $X_{t}$ is given by

$$
\rho_{0}=\left[\rho_{i j}(0)\right]=D^{-1} \Gamma_{0} D^{-1}
$$


where

$\rho_{i j}(0)=\rho_{j i}(0)$ and $-1 \leq \rho_{i j}(0) \leq 1$ and $\rho_{i i}(0)=1$

for $1 \leq i, j \leq k$.

Thus $\rho(0)$ is a symmetric diagonal matrix with unit elements. This is used to measure the strength of the linear dependence between the time series variables.

The $\boldsymbol{L a g}-\boldsymbol{l}$ cross-covariance matrix of $X_{t}$ is given by

$$
\Gamma_{l}=\left[\Gamma_{i j}(l)\right]=E\left(\left[X_{t}-\mu\right]\left[X_{t-l}-\mu\right]^{\prime}\right)
$$

where the $(i, j)^{\text {th }}$ element of $\Gamma_{l}$ is the covariance of $X_{i t}$ and $X_{j, t-l}$.

And the $l a g-l$ cross-correlation matrix of $X_{t}$ is defined as

$\rho_{l}=\left[\rho_{i j}(l)\right]=D^{-1} \Gamma_{l} D^{-1}$ the cross covariance matrix can be estimated.

Given a time series $X_{t}$, The Vector Autoregressive (VAR) model of order 1 or VAR(1) is defined as:

$$
X_{t}=\phi_{0}+\Phi X_{t-1}+a_{t}
$$

where $\phi_{0}$ Is a $\mathrm{k}$-dimensional vector, $\Phi$ is a $k \times k$ matrix and $\left\{a_{t}\right\}$ is a sequence of serially uncorrelated random vectors with mean zero and covariance matrix $\Sigma$, which is required to be positive definite. Ang. et al (2003),[1]. Therefore, for a VAR(1) with

$$
k=3, \quad X_{t}=\left(X_{1 t}, X_{2 t}, X_{3 t}\right)^{\prime} \text { and } a_{t}=\left(a_{1 t}, a_{2 t}, a_{3 t}\right)^{\prime}
$$

Hence, we have the following equations:

$X_{1 t}=\phi_{10}+\Phi_{11} X_{1, t-1}+\Phi_{12} X_{2, t-1}+\Phi_{13} X_{3, t-1}+a_{1 t}$

$X_{2 t}=\phi_{20}+\Phi_{21} X_{1, t-1}+\Phi_{22} X_{2, t-1}+\Phi_{23} X_{3, t-1}+a_{2 t}$

$X_{3 t}=\phi_{30}+\Phi_{31} X_{1, t-1}+\Phi_{32} X_{2, t-1}+\Phi_{33} X_{3, t-1}+a_{3 t}$

Where $\Phi_{i j}$ is the $(i, j)^{t h}$ element of $\Phi$ and $\phi_{i 0}$ is the $i^{\text {th }}$ element of $\phi_{0}$.

\section{The Error Correction Model}

Cointegration is a relationship between two nonstationary, I(1), variables (Reinsel, 1990)[2]. These variables share a common trend and tend to move together in the long-run. A dynamic relationship between $\mathrm{I}(0)$ variables which embeds a cointegrating relationship known as the short-run error correction model.

Consider a k-dimensional VAR(p) time series $X_{t}$ then;

$$
X_{t}=\phi_{0}+\Phi_{1} X_{t-1}+---+\Phi_{p} X_{t-p}+a_{t}
$$

Then an error correction model (ECM) for the $\operatorname{VAR}(\mathrm{p})$ is given by

$\Delta X_{t}=\phi_{0}+\pi X_{t-1}+\Phi_{1}^{*} \Delta X_{t-1}+\cdots+\Phi_{p-1}^{*} \Delta X_{t-p+1}+a_{t}$ where

$$
\pi=\alpha \beta^{\prime}=\Phi_{p}+\Phi_{p-1}+\cdots+\Phi_{1}-I=-\Phi
$$

\section{Determination of the Lag Length}

The optimum lag length was selected based on the selection procedure proposed by Akaike Information
Criterion (AIC), Schwarz Information Criterion (SIC) and Quinn Information Criterion (HQIC).

\section{Results and Discussion}

Descriptive statistic of prices of tea, rubber and coconut (in Rupees) between 1966-2009 is given in Table 1.

Table 1. Descriptive statistical of return on tea, rubber and coconut (in Rupees)

\begin{tabular}{|c|c|c|c|c|c|c|c|}
\hline Variable & Obs & Mean & $\begin{array}{c}\text { Std. } \\
\text { Dev }\end{array}$ & Q1 & Min & Q3 & Max \\
\hline $\begin{array}{c}\text { Tea } \\
\text { Price }\end{array}$ & 44 & 27645 & 21219 & 8730 & 3300 & 42424 & 96170 \\
\hline $\begin{array}{c}\text { Rubber } \\
\text { Price }\end{array}$ & 44 & 44353 & 60100 & 4383 & 1740 & 55378 & 245750 \\
\hline $\begin{array}{c}\text { Coconut } \\
\text { Price }\end{array}$ & 44 & 6437 & 7480 & 670 & 180 & 9944 & 32354 \\
\hline
\end{tabular}

From Table 1, it can be seen that the average price of tea between 1966-2009 was Rs 27645 per tonne with a minimum price of Rs 3300 and maximum of Rs 96170 per tonne. Also it could be observed that the average price of rubber between 1966-2009 was Rs 44353 per tonne with a minimum price of Rs 1740 and maximum of Rs 245750 per tonne. An average coconut price was Rs 6437 per tonne, with a minimum price of Rs 180 per tonne and a maximum price of Rs 32354 per tonne.

\section{Dickey Fuller Unit-root Test}

In order to establish the order of the series, the Augmented Dickey Fuller unit-root test was used to investigate whether the series of the prices of tea, rubber and coconut were stationary. Results are given in Table 2.

Table 2. Dickey-Fuller test for unit root results

\begin{tabular}{|c|c|c|c|c|c|}
\hline Variable & $\begin{array}{c}\text { Test } \\
\text { statistic }\end{array}$ & $\begin{array}{c}1 \% \\
\text { critical } \\
\text { value }\end{array}$ & $\begin{array}{c}5 \% \\
\text { critical } \\
\text { value }\end{array}$ & $\begin{array}{c}10 \% \\
\text { critical } \\
\text { value }\end{array}$ & p-value \\
\hline Tea & -2.072 & -3.628 & -2.950 & -2.608 & 0.2559 \\
\hline Rubber & 0.268 & -3.628 & -2.950 & -2.608 & 0.9758 \\
\hline Coconut & -0.024 & -3.628 & -2.950 & -2.608 & 0.9565 \\
\hline
\end{tabular}

Considering the results from Table 2, since $\mathrm{p}$-value $(\mathrm{P}>0.05)$ at all the critical values, we fail to reject the null hypothesis that there is unit root at all the critical values ( $1 \%$, $5 \%$, and $10 \%$ ) for all the variables.

\section{Model Selection for the Individual Assets}

Using Akaike Information Criterion and Schwarz Information Criterion as selection criteria for the individual asset model is summarized below:

\section{Model for Tea Price}

$\operatorname{ARIMA}(0,1,0)$

$\mathrm{AIC}=938.54 \mathrm{AICc}=938.64 \mathrm{BIC}=940.3 \log$ likelihood $=$ $-468.27$

The best model based on the selection criteria for tea price 
was $\operatorname{ARIMA}(0,1,0)$.

Model for rubber price is given in Table 3.

Table 3. Model for rubber price

\begin{tabular}{|c|c|c|c|c|c|}
\hline $\begin{array}{c}\text { ARIMA (3, 1, } \\
\text { 1) }\end{array}$ & Constant & ar1 & ar2 & ar3 & ma1 \\
\hline Coefficients & 3327.862 & 0.454 & 0.4588 & -0.7935 & 0.0005 \\
\hline $\begin{array}{c}\text { Standard } \\
\text { Error }\end{array}$ & 2379.602 & 0.223 & 0.1379 & 0.1364 & 0.2757 \\
\hline
\end{tabular}

$\mathrm{AIC}=952.6, \quad \mathrm{AICc}=954.93 \quad, \quad \mathrm{BIC}=963.16$

$\log$ likelihood $=-470.3$

From Table 3 , the best model for the rubber price is ARIMA $(3,1,1)$ based on the selection criteria.

Model for coconut price is given in Table 4.

Table 4. Model for coconut price returns

\begin{tabular}{|c|c|c|c|c|}
\hline ARIMA $(0,1,3)$ & Constant & ma1 & ma2 & ma3 \\
\hline Coefficients & 680.972 & -0.3992 & -0.2711 & 0.7898 \\
\hline Standard Error & 332.6319 & 0.1060 & 0.2480 & 0.211 \\
\hline
\end{tabular}

$\mathrm{AIC}=789.06, \quad \mathrm{AICc}=790.68, \quad \mathrm{BIC}=797.86, \quad \log$ likelihood $=-389.53$

From Table 4, the best model for the coconut price is ARIMA $(0,1,3)$ based on the selection criteria.

\section{Johansen tests for cointegration}

We investigate, whether tea, rubber and coconut prices have a long-run equilibrium by performing a cointegration test (Johansen, 1988) [10]. Johansen tests results for cointegration are given in Table 5 .
Table 5. Johansen tests for cointegration

\begin{tabular}{|c|c|c|c|c|c|}
\hline $\begin{array}{c}\text { Maximum } \\
\text { rank }\end{array}$ & Parms & LL & Eigenvalue & $\begin{array}{c}\text { Trace } \\
\text { statistics }\end{array}$ & $\begin{array}{c}5 \% \\
\text { critical } \\
\text { value }\end{array}$ \\
\hline 0 & 12 & -1303.5 & & 36.8114 & 29.68 \\
\hline 1 & 17 & -1288.8 & 0.50493 & $7.2828 *$ & 15.41 \\
\hline 2 & 20 & -1285.8 & 0.13325 & 1.2767 & 3.76 \\
\hline 3 & 21 & -1285.2 & 0.02994 & & \\
\hline
\end{tabular}

We observe in Table 5 that, at Rank (0) the Trace statistic is 36.8 which is greater than 29.68; hence we reject the hypothesis at $5 \%$ critical value that there is no cointegration between tea, rubber and coconut. That is there is a long run association. But at all the other Ranks, the Trace values were less than the $5 \%$ critical values. Therefore, we used the Vector Error Correction model (VECM) (Granger et al., 1987) [8].

\section{Multivariate Analysis for the VECM- Model}

Lag selection order

Using the lag selection procedure for the maximum lags for the VECM-model, we used the AIC, HQIC, and SBIC selection criteria. The summary is given in Table 6 .

With tea, rubber and coconut prices as endogenous and the constant as exogenous factors, using the lag selection criteria of AIC, HQIC and SBIC, a maximum of optimal seven lags (7) were selected for the VEC-model as shown on Table 6.

\section{Vector Error Correction model (VECM)}

Table 7 is showing the summary of the optimum model selection for the VECM - Model based on the selection criteria AIC, SBIC, and $\mathrm{HQIC}$, respectively.

$$
\mathrm{AIC}=56.26621, \mathrm{SBIC}=58.96558, \mathrm{HQIC}=57.21786,
$$
Log likelihood $=-978.924$

Table 6. Lag selection using AIC, HQIC and SBIC

\begin{tabular}{|c|c|c|c|c|c|c|c|c|}
\hline Lag & LL & LR & df & P & FPE & AIC & HQIC & SBIC \\
\hline 0 & -1221.49 & & & & $1 \mathrm{e}+25$ & 66.1886 & 66.2346 & 66.3192 \\
\hline 1 & -1151.29 & 140.4 & 9 & 0.000 & $4.1 \mathrm{e}+23$ & 62.8805 & 63.0647 & 63.4029 \\
\hline 2 & -1138.18 & 26.211 & 9 & 0.002 & $3.3 \mathrm{e}+23$ & 62.6586 & 62.9809 & 63.5729 \\
\hline 3 & -1115.62 & 45.131 & 9 & 0.000 & $1.6 \mathrm{e}+23$ & 61.9253 & 62.3858 & 63.2315 \\
\hline 4 & -1062.35 & 106.54 & 9 & 0.000 & $1.6 \mathrm{e}+22$ & 59.5324 & 60.1311 & 61.2304 \\
\hline 5 & -1028.42 & 67.856 & 9 & 0.000 & $4.5 \mathrm{e}+21$ & 58.185 & 58.9217 & 60.2748 \\
\hline 6 & -1001.78 & 53.278 & 9 & 0.000 & $2.0 \mathrm{e}+21$ & 57.2315 & 58.1064 & 59.7132 \\
\hline 7 & -972.574 & 58.419 & 9 & 0.000 & $8.3 \mathrm{e}+20$ & 56.1391 & 57.1522 & 59.0126 \\
\hline
\end{tabular}

Table 7. VECM -model Selection

\begin{tabular}{|c|c|c|c|c|c|}
\hline Equation & Parms & RMSE & R-sq & chi2 & P $>$ chi2 \\
\hline D_Tea & 20 & 6228.82 & 0.9089 & 169.6666 & 0.0000 \\
\hline D_Rubber & 20 & 5481.39 & 0.9628 & 439.7099 & 0.0000 \\
\hline D_Coconut & 20 & 924.029 & 0.9526 & 341.4395 & 0.0000 \\
\hline
\end{tabular}


From Table 7 with root mean square error (RMSE) of 6228.82, 5481.39 and 924.03 for tea, rubber and coconut and R-square of $0.91,0.96$ and 0.95 for tea, rubber and coconut, respectively. The selected model approximately explains about $93 \%$ of the variation of the data.

\section{Analysis of the equations}

Tea parameter estimates

The summary of the parameter estimation for tea as the dependent variable is given in Table 8 .

Table 8. Estimated coefficients for tea prices as dependent variable

\begin{tabular}{|c|c|c|c|c|}
\hline $\begin{array}{c}\text { Variables } \\
\text { D_Tea }\end{array}$ & Coef. & Std. Err. & $\mathrm{z}$ & $\mathrm{P}>|\mathrm{z}|$ \\
\hline Tea & & & & \\
\hline L3D & .5559323 & .2282418 & 2.44 & 0.015 \\
\hline L4D & .924374 & .3188231 & 2.90 & 0.004 \\
\hline L6D & .6988486 & .3490157 & 2.00 & 0.045 \\
\hline Rubber & & & & \\
\hline L2 D & 1.191664 & 4140998 & 2.88 & 0.004 \\
\hline L3D & 2.196163 & .6037656 & 3.64 & 0.000 \\
\hline L6D & -2.044941 & .9123783 & -2.24 & 0.025 \\
\hline
\end{tabular}

In Table 8, the error correction term was not significant hence there is no long run causality between tea, rubber and coconut. Tea depends on it lags 3,4 and 6 difference and on lags 2,3, and 6 differenced of rubber, hence there is a short run causality between tea and rubber but not coconut.

\section{Coconut parameter estimates}

The summary of the parameter estimation for coconut prices as the dependent variable is given in Table 9.

From Table 9, the error correction term is significant; hence there is long run causality between rubber, tea and coconut. Coconut depends on tea at lag 1, rubber at lags 2 and 5 and coconut at lags 1 and 2 difference, respectively. Hence there is short run causality between rubber, tea and coconut.

Table 9. Estimated coefficients for coconut prices as the dependent variable

\begin{tabular}{|c|c|c|c|c|}
\hline $\begin{array}{c}\text { Variables }- \\
\text { D_Coconut }\end{array}$ & Coef. & Std. Err. & $\mathrm{z}$ & $\mathrm{P}>|\mathrm{z}|$ \\
\hline L1 & 1.248619 & .6313494 & 1.98 & 0.048 \\
\hline Tea & & & & \\
\hline LD & .1103913 & .0471179 & 2.34 & 0.019 \\
\hline Rubber & & & & \\
\hline L2D & .1759813 & .0614307 & 2.86 & 0.004 \\
\hline L5D & .3823159 & .1393782 & 2.74 & 0.006 \\
\hline Coconut & & & & \\
\hline LD & -1.810611 & .6487472 & -2.79 & 0.005 \\
\hline L2D & -2.086044 & .6913349 & -3.02 & 0.003 \\
\hline
\end{tabular}

\section{Rubber parameter estimates}

The summary of the parameter estimation for rubber prices as the dependent variable is given in Table 10 .

Table 10. Estimated coefficients for rubber prices as the dependent variable

\begin{tabular}{|c|c|c|c|c|}
\hline $\begin{array}{c}\text { Variables } \\
\text {-D_Rubber }\end{array}$ & Coef. & Std. Err. & $\mathrm{z}$ & $\mathrm{P}>|\mathrm{z}|$ \\
\hline L1 & 26.74918 & 3.745197 & 7.14 & 0.000 \\
\hline \multicolumn{5}{|l|}{ Tea } \\
\hline LD & .5514238 & .2795056 & 1.97 & 0.049 \\
\hline L2D & .6602082 & .2713432 & 2.43 & 0.015 \\
\hline L3D & .9596806 & .2008539 & 4.78 & 0.000 \\
\hline L4D & 1.061325 & .2805658 & 3.78 & 0.000 \\
\hline L5D & 1.30957 & .2111087 & 6.20 & 0.000 \\
\hline L6D & .9580264 & .3071354 & 3.12 & 0.002 \\
\hline \multicolumn{5}{|l|}{ Rubber } \\
\hline LD & 2.681794 & .4209982 & 6.37 & 0.000 \\
\hline L2D & 3.333131 & .3644098 & 9.15 & 0.000 \\
\hline L3D & 1.822291 & .5313165 & 3.43 & 0.001 \\
\hline L4D & 1.672864 & .5021341 & 3.33 & 0.001 \\
\hline \multicolumn{5}{|l|}{ Coconut } \\
\hline LD & -25.48814 & 3.848401 & -6.62 & 0.000 \\
\hline L2D & -21.77069 & 4.101034 & -5.31 & 0.000 \\
\hline L3D & -17.72586 & 3.393377 & -5.22 & 0.000 \\
\hline L4D & -14.8394 & 3.247015 & -4.57 & 0.000 \\
\hline L5D & -8.10452 & 2.134342 & -3.80 & 0.000 \\
\hline L6D & -5.199878 & 2.312453 & -2.25 & 0.025 \\
\hline
\end{tabular}

From Table 10 above, the error correction term is significant; indicating the existence of long run causality between rubber, coconut and tea. Rubber depends on tea at all the six lags, Rubber at lags 1, 2, 3 and 4 and Coconut at lags 1 and 2, 3, 4, 5, and 6 differences respectively. Hence there is short run causality between rubber, tea and coconut.

\section{Diagnostic Test}

\section{Autocorrelation Test}

Using the Lagrange-multiplier test, we tested for autocorrelation at lags 1 and 2 . Table 11 shows the summary of results:

Table 11. Lagrange-multiplier test for autocorrelation

\begin{tabular}{|c|c|c|c|}
\hline Lag & chi2 & df & Prob $>$ chi2 \\
\hline 1 & 12.8672 & 9 & 0.16871 \\
\hline 2 & 9.7464 & 9 & 0.37140 \\
\hline
\end{tabular}

From Table 11, with probability of 0.0168 and 0.0371 for lags 1 and 2, respectively. This indicates that there is no significant autocorrelation at the lag order. 


\section{Normality Test}

Using Jarque-Bera, we tested for normality in the residuals. Results of Jarque-Bera normality test for the residuals is given in Table 12,

Table 12. Jarque-Bera normality test for the residuals:

\begin{tabular}{|c|c|c|c|}
\hline Equation & chi2 & df & Prob $>$ chi2 \\
\hline D_tea & 0.393 & 2 & 0.82166 \\
\hline D_rubber & 0.869 & 2 & 0.64746 \\
\hline D_coconut & 0.386 & 2 & 0.82443 \\
\hline ALL & 1.648 & 6 & 0.94904 \\
\hline
\end{tabular}

From Table 12, we observed that all the probability values of the variables including the overall have $\mathrm{P}>0.05$, hence the residuals are normally distributed.

\section{Correlation Matrix}

As proposed by Moynihan (1990) [5], the cross-correlation matrix of the variables is summarized in Table 13.

Table 13. Correlation matrix

\begin{tabular}{|c|c|c|c|}
\hline Variable & Coconut & Rubber & tea \\
\hline Coconut & 1.0000 & 0.9395 & 0.4674 \\
\hline Rubber & 0.9395 & 1.0000 & 0.4241 \\
\hline tea & 0.4674 & 0.4241 & 1.0000 \\
\hline
\end{tabular}

From Table 13, the correlation between rubber and coconut is 0.94 . There is an indication of strong positive relationship between the prices of rubber and coconut.

The correlation between coconut and tea prices is 0.47 which is fairly strong. And the correlation between rubber and tea prices is 0.42 which is also fairly strong.

\section{Impulse Responses (IR's)}

The Impulse Response (IR's) is given in Figure 2. The first row shows rubber responses from the shocks of rubber price, coconut price and finally tea prices. The second row shows rubber responses to the shocks of rubber price, coconut price and finally tea prices. The third row shows rubber responses from the shocks of rubber price, coconut price and finally tea prices.

\section{Conclusions}

There is also both long run and short run causality among tea, rubber and coconut prices. The coefficient estimates between tea and rubber are not the same as between rubber and tea at all lags, between tea and coconut, as well as between rubber and coconut. This indicates that there is a feedback relationship between the three series.

From the analysis above it could be observed that the coefficients between any of the variables was not equal to zero, that is, there is an indication of linear dependency of all the variables. We could conclude that the price movement of one market can spread easily and instantly to another market and also there is a fairly strong correlation between the prices of the assets. Therefore, financial markets are more or less dependent on each other; hence there is an interrelationship between variables which can explain the dynamic structure of the financial economy.

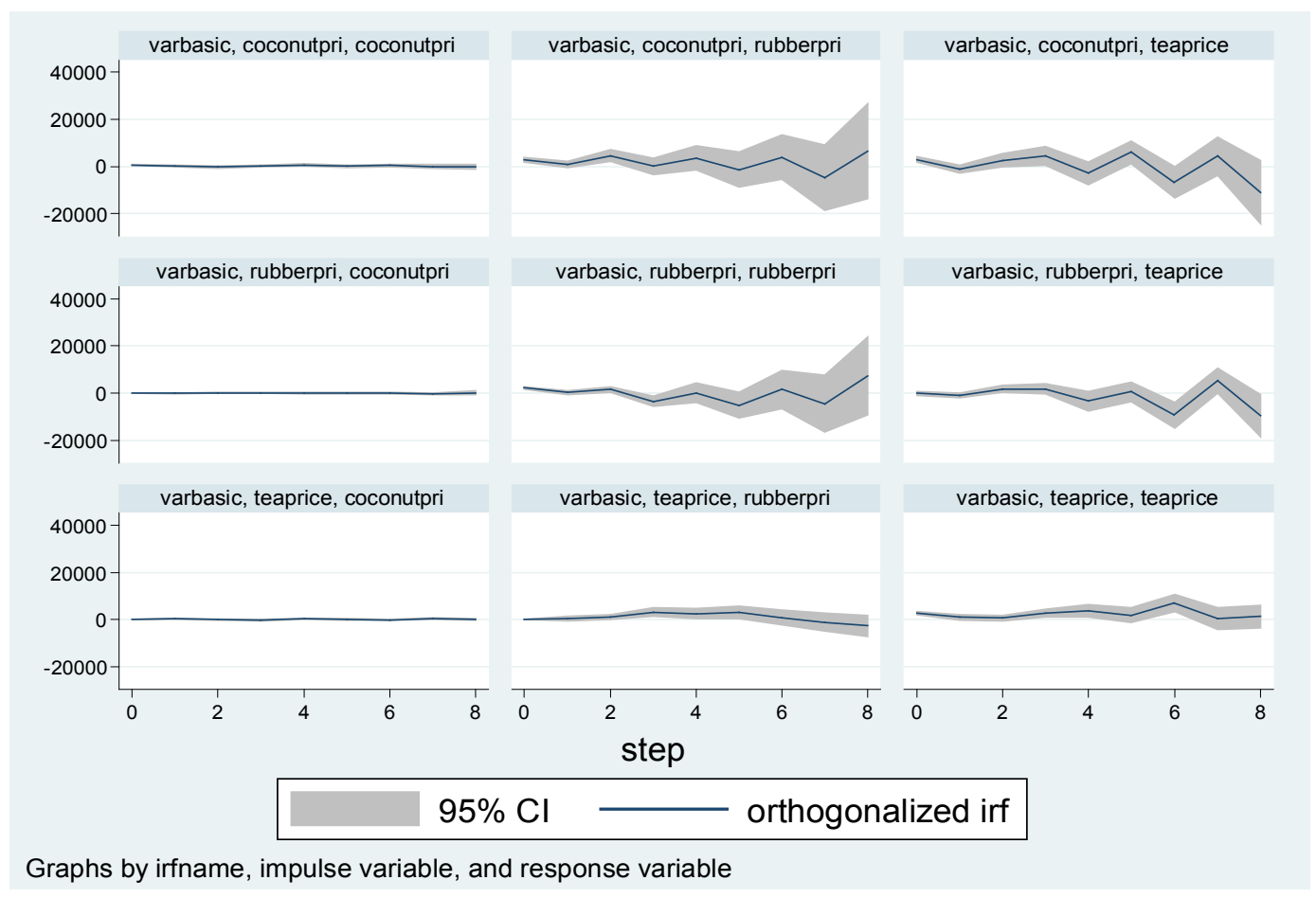

Figure 2. Impulse response (IR's) of rubber, coconut and tea. 


\section{Appendix}

Attached is the time series data of annual prices of tea, rubber and coconut from 1966 - 2009.

\begin{tabular}{|c|c|c|c|}
\hline years & coconut & rubber & tea \\
\hline 1966 & 180 & 1740 & 3470 \\
\hline 1967 & 235 & 1740 & 3300 \\
\hline 1968 & 300 & 1940 & 3850 \\
\hline 1969 & 310 & 2290 & 3370 \\
\hline 1970 & 315 & 2000 & 3600 \\
\hline 1971 & 290 & 1740 & 3990 \\
\hline 1972 & 260 & 1780 & 4170 \\
\hline 1973 & 385 & 2570 & 4160 \\
\hline 1974 & 500 & 2820 & 5850 \\
\hline 1975 & 420 & 2490 & 6120 \\
\hline 1976 & 570 & 4340 & 7790 \\
\hline 1977 & 1010 & 4510 & 13150 \\
\hline 1978 & 970 & 6920 & 11550 \\
\hline 1979 & 1170 & 9150 & 12190 \\
\hline 1980 & 1660 & 10620 & 18330 \\
\hline 1981 & 1930 & 10040 & 20000 \\
\hline 1982 & 1750 & 10180 & 22000 \\
\hline 1983 & 2540 & 13950 & 25000 \\
\hline 1984 & 3870 & 15340 & 27000 \\
\hline 1985 & 2240 & 16800 & 29000 \\
\hline 1986 & 1592 & 18560 & 31320 \\
\hline 1987 & 2855 & 20420 & 32465 \\
\hline 1988 & 4737 & 21900 & 33300 \\
\hline 1989 & 3552 & 23500 & 36840 \\
\hline 1990 & 3419 & 25100 & 42945 \\
\hline 1991 & 4513 & 26800 & 46680 \\
\hline 1992 & 6194 & 28262 & 49660 \\
\hline 1993 & 7773 & 35660 & 50410 \\
\hline 1994 & 6213 & 50340 & 51945 \\
\hline 1995 & 5467 & 72450 & 55070 \\
\hline 1996 & 8333 & 67880 & 62865 \\
\hline 1997 & 9573 & 56710 & 73990 \\
\hline 1998 & 11013 & 49830 & 96170 \\
\hline 1999 & 11547 & 41650 & 17940 \\
\hline 2000 & 8347 & 51380 & 21090 \\
\hline 2001 & 10067 & 46790 & 21050 \\
\hline 2002 & 15773 & 58440 & 21830 \\
\hline 2003 & 14387 & 77880 & 21079 \\
\hline 2004 & 13856 & 98370 & 26430 \\
\hline 2005 & 18065 & 122160 & 27180 \\
\hline 2006 & 17253 & 193720 & 29190 \\
\hline 2007 & 21154 & 216670 & 40860 \\
\hline 2008 & 32354 & 245750 & 45450 \\
\hline 2009 & 24306 & 178370 & 52710 \\
\hline
\end{tabular}

\section{REFERENCES}

[1] Ang, M. Piazzesi, (2003), “A no-arbitrage Vector Autoregression of Term Structure Dynamics with Macroeconomic and Latent Variables", Journal of Monetary Economics 50: 745-787.

[2] Ahn, SK. and G.C. Reinsel (1990), "Estimation for Partially Nonstationary Autoregressive Models", Journal of the American Statistical Association, 85, 813-823.

[3] Anderson, T.W. (1951) "Estimating Linear Restrictions on Regression Coefficients for Multivariate Normal Distributions", Annals of Mathematical Statistics, 22, 327751 .

[4] Anderson, T.W. (1984), "An Introduction to Multivariate Statistical Analysis", 2nd Edition. Wiley: New York.

[5] Andrews, D.W.K. and J.C. Moynihan (1990), "An Improved Heteroskedastic and Autocorrelation Consistent Covariance Matrix Estimator", Cowles Foundation Discussion Paper No. 942, Yale University.

[6] Annual Report (2010-2011), Bogawantalawa Tea Estates Ltd. [on line]. [Accessed on 09.05.2014]. Available at Www.Bogawantalawa.Com/Annual_Report_2010_2011.pdf.

[7] Department of Census and Statistics, Annual Bulletin - 2013, [on line]. [Accessed on 13.05.2014]. Available at www.statistics.gov.lk.

[8] Engle, R. F. and Granger, C. W. J. (1987). "Co-integration and error correction representation, estimation and testing". Econometrica 55: 251-276.

[9] FAOSTAT, Sri Lanka Annual Data(1966-2009),[on line]. [Accessed on 10.02.2014]. Available at http://faostat.fao.org.

[10] Johansen, S. (1988). "Statistical analysis of co-integration vectors". Journal of Economic Dynamics and Control 12: 231-254.

[11] Manual on Agricultural Prices and Marketing - Ministry Of Statistics (2010), [on line]. [Accessed on 03.04.2014]. Available at

Mospi.Nic.In/Mospi.../Manual-On-Agricultural-Prices-AndMarketing.pdf.

[12] Richard A. Johnson, (2012), Applied Multivariate Statistical Analysis, $6^{\text {th }}$ Edition Willy New Delhi :pp 441-453.

[13] Sri Lanka Tea Board: Annual Report. (2010), Sri Lanka Tea Board. 574, Galle Road. Colombo 03. Sri Lanka. Issn: 1391 1414. 